\title{
Sapientia Salomonis (Weisheit Salomos)
}

Eingel., übers. u. mit interpretierenden Essays versehen v. Karl-Wilhelm Niebuhr, Walter Ameling, Folker Blischke, Mareike V. Blischke, Alfons Fürst, Rainer HirschLuipold, Heinz-Günther Nesselrath u.a.

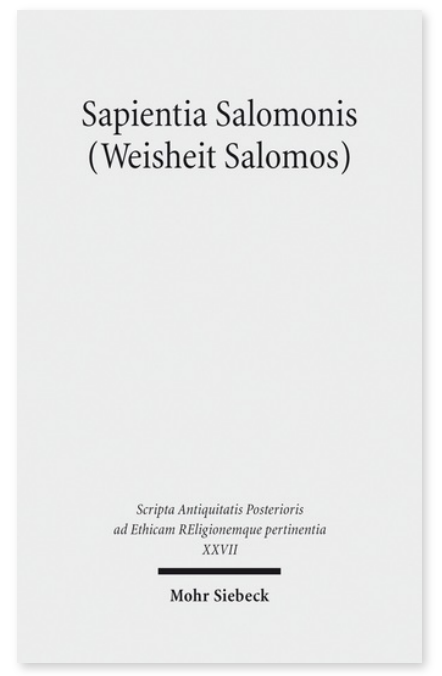

2015. XIII, 350 Seiten. SAPERE XXVII

ISBN 978-3-16-156428-4

DOI 10.1628/978-3-16-156428-4

eBook PDF

ISBN 978-3-16-152808-8

Leinen $94,00 €$
Die Sapientia Salomonis (Weisheit Salomos) wurde seit der Antike in der christlichen Bibel als Teil des Alten Testaments überliefert und hat auf diesem Wege das Denken, die religiösen Vorstellungen und die Ethik der christlichen Welt bis heute tief geprägt. Ursprünglich stammt die Schrift aber aus dem hellenistischen Judentum, wahrscheinlich aus Alexandria um die Zeitenwende, und ist damit ein klassisches Beispiel für die Durchdringung biblisch-jüdischer Überlieferung und griechischrömischer Kultur. Charakteristisch zeigt sich das in der Schrift an der Rezeption biblischer (z.T. schon altorientalischer) Weisheitsüberlieferungen und ihrer Kombination mit Themen, Begriffen und Sprachformen der griechischen Philosophie. Für die Schriften des Neuen Testaments wurde diese Verbindung orientalischer und griechischer Kultur, die wir unter dem Begriff »Hellenismus« fassen, zu einer prägenden geistig-kulturellen Voraussetzung.

Karl-Wilhelm Niebuhr Geboren 1956; 1986 Promotion; 1991 Habilitation; 1994-96 Professor für Biblische Theologie (evangelisch) an der Technischen Universität Dresden; 1997-2022 Professor für Neues Testament an der Friedrich-SchillerUniversität Jena; Präsident des Eastern Europe Liaison Committee (EELC) der Studiorum Novi Testamenti Societas (SNTS). https://orcid.org/0000-0002-8850-7046

Walter Ameling Geboren 1958; Studium der Altertumswissenschaften; 1982 Promotion; 1991 Habilitation; Inhaber des Lehrstuhls für Alte Geschichte in Jena.

Folker Blischke ist Pfarrer der Evangelischen Kirche in Mitteldeutschland (EKM). Seine Forschungsinteressen liegen im Bereich der paulinischen Theologie und der Aufnahme von Denkstrukturen der jüdisch-hellenistischen Welt im Neuen Testament.

Mareike Verena Blischke Geboren 1977; Studium der Theologie; 2007 Promotion; 2008-19 Mitarbeiterin am Seminar für Altes Testament der Georg-August-Universität Göttingen; 2011-19 wissenschaftliche Assistentin am Lehrstuhl von Prof. Hermann Spieckermann; seit 2017 Vikarin in der Evangelischen Kirche in Mitteldeutschland.

Alfons Fürst Geboren 1961; 1996 Promotion (Dr. phil.); 1998 Habilitation (Dr. theol. habil.); 1998-2000 Professor für Kirchengeschichte in Bamberg; seit 2000 Professor für Alte Kirchengeschichte, Patrologie und Christliche Archäologie in Münster; 2010-11 Fellow am Department of Classics in Princeton; 2017-18 Fellow am Institute for Advanced Studies in Jerusalem.

Rainer Hirsch-Luipold Geboren 1967; seit 2011 Ordentlicher Professor für Neues Testament und Antike Religionsgeschichte an der Universität Bern; seit 2015 zusätzlich Extraordinary Professor an der Stellenbosch University (SA), Department of Ancient Studies.

https://orcid.org/0000-0002-6938-268X

Heinz-Günther Nesselrath Geboren 1957; 1976-81 Studium der Klassischen Philologie und der Alten Geschichte an der Universität zu Köln; 1981 Promotion; 1987 Habilitation; 1992-2001 vollamtlicher Professor für Klass. Philologie an der Universität Bern; seit 2001 Universitätsprofessor für Klass. Philologie an der Georg-August-Universität Göttingen.

Maren R. Niehoff Geboren 1963; Ausbildung an der Hebräischen Universität Jerusalem, der Freien Universität in Berlin, Oxford University and Harvard University; seit 2014 Max Cooper Professor im Dept. für Jüdische Philosophie, Hebräische Universität Jerusalem.

https://orcid.org/0000-0002-0815-6929

Friedrich V. Reiterer ist em. Professor für Altes Testament an der Kath.-Theol. Fakultät der Paris-Lodron-Universität Salzburg Seine Forschungsschwerpunkte liegen auf der deuterokanonischen Literatur, insbesondere dem Buch Ben Sira. Er ist Begründer von Deuterocanonical and Cogante Literature Studies und Deuterocanonical and Cogante Literature Yearbook. Zur Zeit bereitet er eine Polyglotte Studientextausgabe zum Buch Ben Sira und eine Theologie des Buches Ben Sira vor.

Jetzt bestellen:

https://mohrsiebeck.com/buch/sapientia-salomonis-weisheit-salomos-9783161564284?no_cache=1

order@mohrsiebeck.com

Telefon: $+49(0) 7071-923-17$

Telefax: $+49(0) 7071-51104$ 